\title{
Ultrasound biomicroscopy of the peripheral retina and the ciliary body in degenerative retinoschisis associated with pars plana cysts
}

Giuseppe Mannino, Romualdo Malagola, Solmaz Abdolrahimzadeh, Gianfrancesco M Villani, Santi M Recupero

\begin{abstract}
Aim-To evaluate the ciliary body and peripheral retina in degenerative retinoschisis associated with pars plana cysts using ultrasound biomicroscopy (UBM). Methods-18 eyes of 12 patients with degenerative retinoschisis associated with pars plana cysts were selected through binocular indirect ophthalmoscopy and Goldmann three mirror lens examination, both with scleral depression. These patients were studied in detail with UBM.

Results-Study of the ciliary body with UBM showed pars plana cysts of different size and uneven shape. In cross sections the morphology of pars plana cysts in detail and the close relation of the cysts with the oral region and the peripheral retina, where areas of cystoid degeneration and retinoschisis were present, were observed. In transverse sections three main morphological aspects of pars plana cysts could be differentiated ("isolated," "confluent," and "clustered" cysts). Furthermore, ultrabiomicroscopy allowed differential diagnosis between retinoschisis and associated retinal detachment in six eyes.

Conclusions-The study of peripheral degenerative retinoschisis and pars plana cysts is possible in vivo by means of UBM, showing the detailed morphology of the lesions (not otherwise evident through ophthalmoscopic examination) and the close relation between pars plana cysts, cystoid degeneration, and peripheral retinoschisis.

(Br f Ophthalmol 2001;85:976-982)
\end{abstract}

Institute of

Ophthalmology,

University of Rome

"La Sapienza," Rome,

Italy

G Mannino

R Malagola

S Abdolrahimzadeh

G M Villani

S M Recupero

Correspondence to:

Professor S M Recupero,

Istituto di Oftalmologia,

Universita' di Roma, "La

Sapienza," Policlinico

Umberto I, Viale del

Policlinico 155, Roma

00161 , Italy

santi.recupero@uniroma1.it

Accepted for publication 26 February 2001 esis of these degenerative processes, as diff ent theories have been put forward but none has proved to be unquestionable. ${ }^{131617}$ The pathogenetic mechanism has been attributed to circulatory disturbances, the motility of accommodation, vitreous traction, holes in the inner lamina, autolysis of retinal cells in the peripheral retina, osmotic procedures, and transudate from the choriocapillaris. ${ }^{17}$ Histochemical studies have shown that the content of the cystoid spaces and schisis of the peripheral retina is hyaluronic acid. ${ }^{18}$ The same material had been found in pars plana cysts, ${ }^{18-20}$ where it would accumulate owing to an active secretion from the non-pigment epithelium of the ciliary body and especially of the pars plana. ${ }^{19}$ Subsequent splitting of the ciliary pigment and non-pigment epithelial layers would lead to pars plana cyst formation. Once the similarity of the content of pars plana cysts and of cystoid degeneration and retinoschisis of the peripheral retina had been disclosed, the hypothesis that retinoschisis also was caused by a secretory process was advanced. ${ }^{17}{ }^{21}$ However, no periodic acid Schiff (PAS) positive cells could be demonstrated within the walls of retinoschisis. ${ }^{17}$ In the past, glial cells, such as astrocytes and Mueller cells, were suggested as a possible source of hyaluronic acid. ${ }^{16}$

Pars plana cysts have been reported as common alterations of the posterior ciliary body ${ }^{1922}$ of no clinical concern ${ }^{43}$ that can be seen at indirect ophthalmoscopy and Goldmann three mirror examination. ${ }^{424}{ }^{25}$ Histologically, ${ }^{22}$ they usually result from the separation of the two epithelial cell layers of the pars plana; less frequently, small cysts derive from the coalescence of vacuoles within adjacent nonpigmented cells or alternatively from a general loosening of cells within an area of epithelial proliferation. In a histopathological study, the cysts were demonstrated to continue posteriorly with an area of cystoid degeneration of the peripheral retina. ${ }^{23}$

Ultrasound biomicroscopy (UBM) is a painless and non-invasive diagnostic technique that offers high resolution imaging. ${ }^{11}$ It has gained much popularity not only in the diagnosis of anterior segment disorders, ${ }^{11}{ }^{2627}$ among which are cysts of different origin, ${ }^{28}$ but also of the pars plana and peripheral retina. ${ }^{11}{ }^{12}$ Recently this technique has been applied to the diagnosis of retinal detachment, ${ }^{12}{ }^{29}$ retinoschisis, ${ }^{12}$ and detachment of the ciliary epithelium among other conditions. ${ }^{30} 31$

High resolution imaging of the peripheral retina and the ciliary body permits study of the morphology of these regions in cases of degenerative retinoschisis in vivo, providing interesting clues to the clinical and physiopathological 
understanding of this condition. In the present report, UBM was added to clinical examination to better identify and evaluate the location and extension of degenerative retinoschisis. Furthermore, the entire ciliary body, pars plana, and pars plicata were studied in detail.

\section{Methods}

Eighteen eyes of 12 patients with degenerative retinoschisis associated with pars plana cysts were studied. Six were males and six females, with an age range from 25 to 78 years (mean 57.5 years, SD 13.97). Best corrected visual acuity was $20 / 20$ in all patients.

Six patients had been diagnosed with bilateral retinoschisis and six had been diagnosed with unilateral retinoschisis. They were submitted to binocular indirect ophthalmoscopy and Goldmann three mirror lens examination, both with scleral depression. UBM of the peripheral retina and the ciliary body was performed on all eyes. The device (UBM 840 System, Humphrey Instruments, Inc, San Leandro, CA, USA) was adjusted to operate on a $50 \mathrm{MHz}$, high $(2.5 \times 2.5 \mathrm{~mm})$ or medium $(5$ $\times 5 \mathrm{~mm})$ scan format, with a resolution of 50 $\mu \mathrm{m}$. The theory and technique of UBM is well described in previous works. ${ }^{11} 262732$

To achieve the best imaging of the peripheral retina $24 \mathrm{~mm}$ eye cups or at times a water bath formed with an operating room drape, colloidon around the eye, and a wire speculum, were used. The coupling medium between the eye and the UBM probe was either saline solution, $2.5 \%$ methylcellulose, or both. The distance of the probe from the eye surface was $2-3 \mathrm{~mm}$. The patient's cooperation was always needed as imaging of the pars plana and the peripheral retina is gaze dependent.

\section{Results}

The peripheral retinal lesions and ciliary body changes are shown in detail in the Table 1.
For both pars plana cysts and retinoschisis location was prevalent in the temporal quadrants, the upper and lower temporal quadrant being involved almost at the same rate. In six eyes, retinal detachment showed a similar pattern of distribution.

Pars plana cysts varied in size and shape. The cross sectional images showed that the cysts emerged from the posterior third of the pars plana in the majority of cases (16/18 eyes) to extend with a fairly bollous profile to the ora serrata (Figs 1A, 2A). This presented, at times, a band of microcystic degeneration, where hyperreflective strands of tissue split the microcysts (Fig 1A). Beyond the ora, areas of peripheral retinoschisis were clearly imaged as a single thin hyperreflective layer (Figs 1A, 2A, $3 \mathrm{~A})$; thus, UBM examination confirmed the ophthalmoscopic findings in all eyes. It was notable that pars plana cysts were large and numerous in the same areas where retinoschisis was located. Retinoschisis and pars plana cysts were found to be adjacent to each other (Fig 2A) and sometimes associated through a band of microcystic degeneration in between (Fig 1A).

In transverse sections three main morphological patterns of pars plana cysts could be distinguished:

(1) "isolated" cysts, either adjacent to each other or separated by intact areas of ciliary epithelium, presenting an internal wall with a smooth profile and a regular single convexity towards the vitreous body (Fig 3C);

(2) "confluent" cysts with an irregular profile of the internal wall which formed a double convexity towards the vitreous body (Fig 1C); (3) "clustered" cysts, relatively the largest of the three types, extending for a few millimetres, defined by a continuous but ragged internal lamina, presenting multiple convexities towards the vitreous (Figs 1D, 2B, 3D).

On transverse sections, areas of cystoid degeneration in the oral region (Fig $1 \mathrm{E}$ ) and

Table 1 Eighteen eyes of 12 patients with degenerative retinoschisis

\begin{tabular}{|c|c|c|c|c|c|c|}
\hline & Sex & Age & Eye & Refraction & Peripheral retinal lesions & Ciliary body changes \\
\hline 1 & M & 46 & $\mathrm{RE}$ & +0.50 cil $(90)$ & $\begin{array}{l}\text { RS from } 9 \text { to } 2 \mathrm{hr} \text { with OLB at } 12 \mathrm{hr} \text { and } \mathrm{RD} \\
\text { from } 10 \text { to } 2 \mathrm{hr} \text {; RS from } 6 \text { to } 8.30 \mathrm{hr}\end{array}$ & Pars plana cysts in UN, UT, and LT quadrants \\
\hline & & & LE & +0.75 cil $(70)$ & RS from 12 to $2 \mathrm{hr} ; \mathrm{RS}$ from 4 to $6 \mathrm{hr}$ & Pars plana cysts in UT and LT quadrants \\
\hline 2 & $\mathrm{M}$ & 70 & RE & $-1.25 \mathrm{sf}$ & RS in UT quadrant & Pars plana cysts in UT quadrant \\
\hline 3 & M & 67 & LE & $+3.25 \mathrm{sf}=+1 \mathrm{cil}(100)$ & $\begin{array}{l}\text { RS from } 12 \text { to } 3 \mathrm{hr} \text {; RS from } 4 \text { to } 7 \mathrm{hr} \text { with OLB } \\
\text { at } 7 \mathrm{hr} \text { and } \mathrm{RD} \text { posteriorly exceeding the RS }\end{array}$ & Pars plana cysts in UT quadrant \\
\hline 4 & $\mathrm{~F}$ & 57 & $\mathrm{RE}$ & Unaided & $\begin{array}{l}\text { RS from } 6 \text { to } 9 \mathrm{hr} \text { with OLB at } 8 \mathrm{hr} \text { and RD from } \\
6.30 \text { to } 9 \mathrm{hr}\end{array}$ & Pars plana cysts and microcysts in LT quadrant \\
\hline & & & $\mathrm{LE}$ & Unaided & $\begin{array}{l}\text { RS from } 11 \text { to } 2 \mathrm{hr} \text {; RS from } 4 \text { to } 7 \mathrm{hr} \text { with two } \\
\text { large OLBs at } 5 \text { and } 6 \mathrm{hr} \text { along the posterior edge } \\
\text { of the schisis }\end{array}$ & Pars plana cysts in UT quadrant \\
\hline 5 & $\mathrm{~F}$ & 66 & $\mathrm{RE}$ & $+2.50 \mathrm{sf}$ & $\begin{array}{l}\text { RS in temporal quadrants with OLB and RD in } \\
\text { UT quadrant }\end{array}$ & Pars plana cysts and microcysts in UT quadrant \\
\hline & & & LE & $+2.50 \mathrm{sf}$ & $\mathrm{RS}$ in UT and LT quadrants & Pars plana cysts in UT and LT quadrants \\
\hline 6 & $\mathrm{M}$ & 49 & LE & $+1.50 \mathrm{sf}=+0.50 \mathrm{cil}(170)$ & RS in LT quadrant & Pars plana cysts in LT quadrant \\
\hline 7 & M & 78 & $\mathrm{RE}$ & $-0.50 \mathrm{sf}=+1.25 \mathrm{cil}(180)$ & $\mathrm{RS}$ in all quadrants at $360^{\circ}$ & Cysts from the pars plicata to the pars plana at $360^{\circ}$ \\
\hline & & & LE & $-0.25 \mathrm{sf}=+1.25 \operatorname{cil}(180)$ & RS at $360^{\circ}$, especially in lower quadrants & Cysts as in RE (see above), especially in lower quadrants \\
\hline 8 & $\mathrm{M}$ & 50 & LE & $+2 \mathrm{sf}$ & Small RS from 12 to $2 \mathrm{hr}$ & Pars plana cysts and microcysts in UT quadrant \\
\hline 9 & $\mathrm{~F}$ & 25 & LE & $-0.5 \mathrm{sf}$ & RS from 3 to $6 \mathrm{hr}$ with tiny ILBs & Shallow pars plana cyst in LT quadrant \\
\hline 10 & $\mathrm{~F}$ & 58 & $\begin{array}{l}\mathrm{RE} \\
\mathrm{LE}\end{array}$ & $\begin{array}{l}+2.25 \mathrm{sf} \\
+2\end{array}$ & $\begin{array}{l}\text { RS from } 7 \text { to } 9 \mathrm{hr} \\
\text { RS from } 4 \text { to } 7 \mathrm{hr}\end{array}$ & $\begin{array}{l}\text { Pars plana cysts in LT quadrant } \\
\text { Pars plana cysts in LT and LN quadrants }\end{array}$ \\
\hline 11 & $\mathrm{~F}$ & 67 & $\begin{array}{l}\mathrm{RE} \\
\mathrm{LE}\end{array}$ & $\begin{array}{l}\text { Unaided } \\
\text { Unaided }\end{array}$ & $\begin{array}{l}\text { RS from } 6 \text { to } 9 \mathrm{hr} \text { with OLB and RD } \\
\text { RS from } 3 \text { to } 6 \mathrm{hr}\end{array}$ & $\begin{array}{l}\text { Pars plana cysts in LT quadrant } \\
\text { Shallow cleavage and cysts of the pars plana from LT to } \\
\text { UT and UN quadrants }\end{array}$ \\
\hline 12 & $\mathrm{~F}$ & 57 & $\mathrm{LE}$ & $+1 \mathrm{sf}=+0.50 \mathrm{cil}(180)$ & $\begin{array}{l}\text { RS from } 1 \text { to } 5 \mathrm{hr} \text { with two small OLBs and initial } \\
\text { RD in LT quadrant }\end{array}$ & Small pars plana microcysts in UT and LT quadrants \\
\hline
\end{tabular}

$\mathrm{hr}=$ clock hours; $\mathrm{RS}=$ retinoschisis; OLB: outer retinal layer break ILB = inner retinal layer break; $\mathrm{RD}=$ retinal detachment

Eye quadrants: $\mathrm{UT}=$ upper temporal; $\mathrm{LT}=$ lower temporal; $\mathrm{LN}=$ lower nasal; $\mathrm{UN}=$ upper nasal. 
retinoschisis of the extreme periphery (Fig 2C) could also be observed.

In one patient (no 7) cysts of the ciliary processes and of the pars plana were observed in both eyes. In some cross sectional images these cysts were seen to extend from the pars plicata to the pars plana closely following each other. The pars plicata was normal in the other patients (Figs 1B, 3B).

In six eyes with ophthalmoscopically detected schisis detachment it was possible to confirm the diagnosis at UBM and to differentiate the

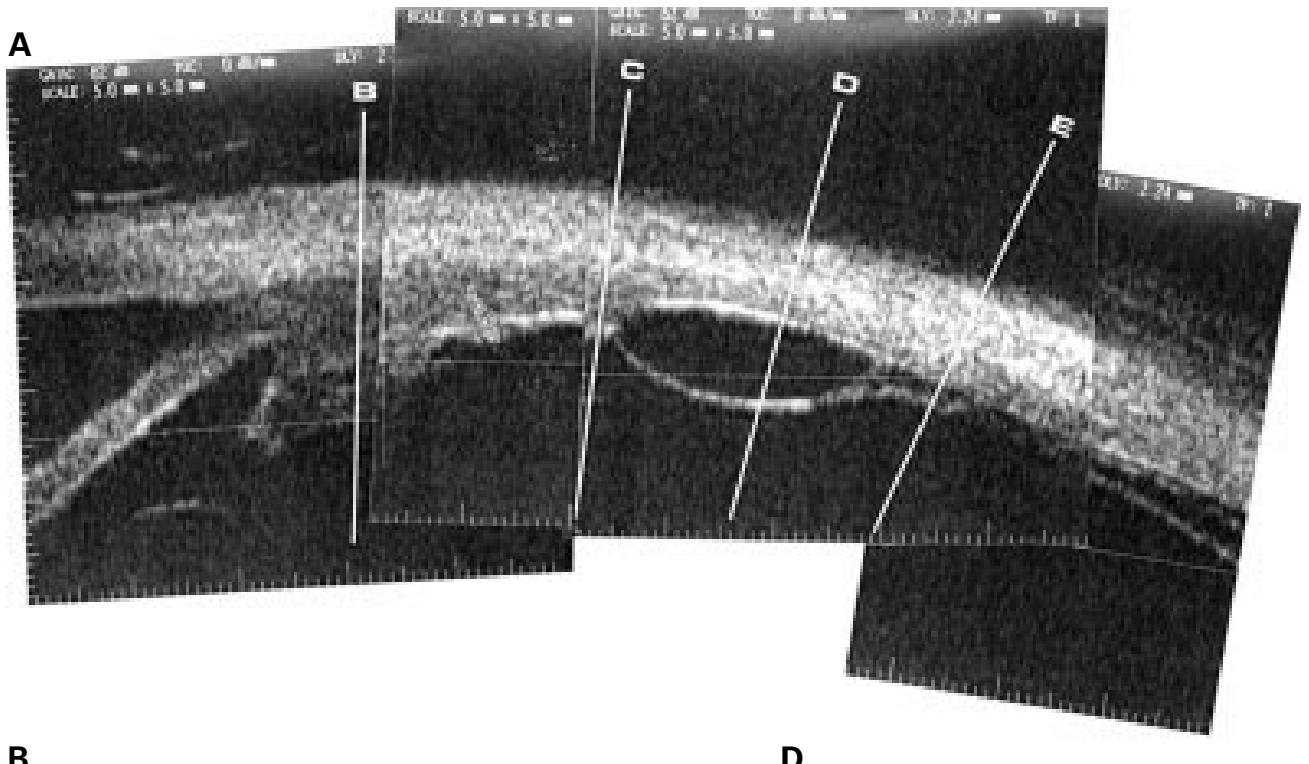

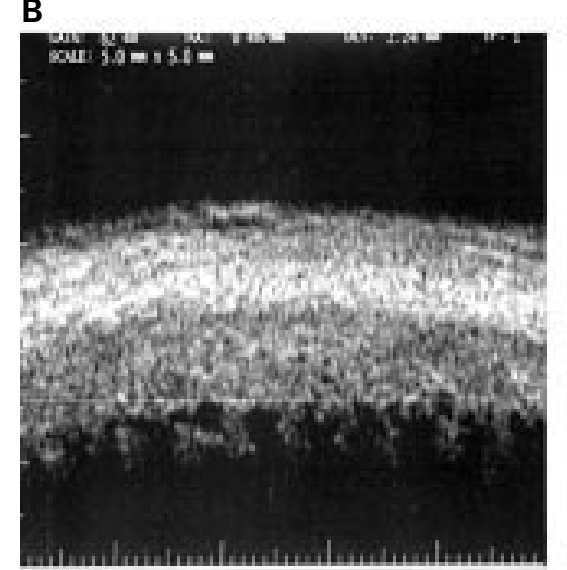

Tristos?

c

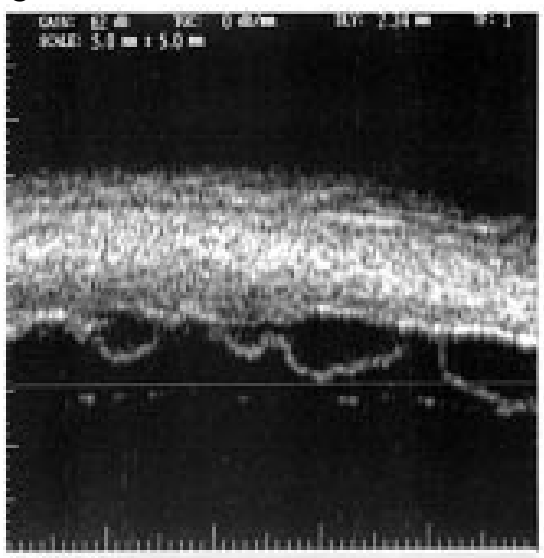

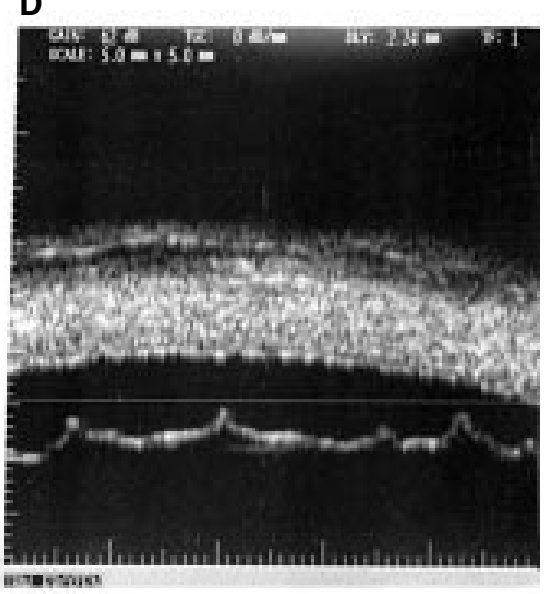

E

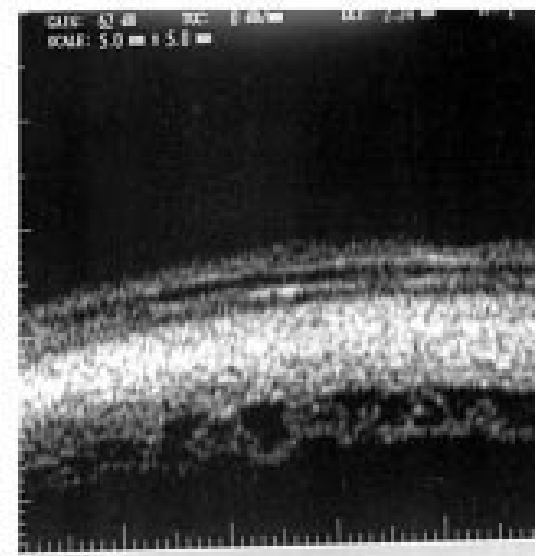

ตT:

Figure 1 Patient no 1, left eye. (A) Composite cross sectional UBM image (1 o'clock). A large cyst of the posterior portion of the pars plana ciliaris can be seen extending to the ora serrata; a hyperreflective bridge is evident. Microcysts at the ora serrata and retinoschisis in the very peripheral retina can be observed. (B) Transverse section of the pars plicata ciliaris. Ciliary processes. (C) Transverse section of the pars plana ciliaris. Small cysts in an early stage. (D) Transverse section of evident. (E) Transverse section of the ora serrata. Cystoid degeneration of the extreme retinal periphery; numerous microcysts with hyperreflective bridges separating the cavities can be seen. 


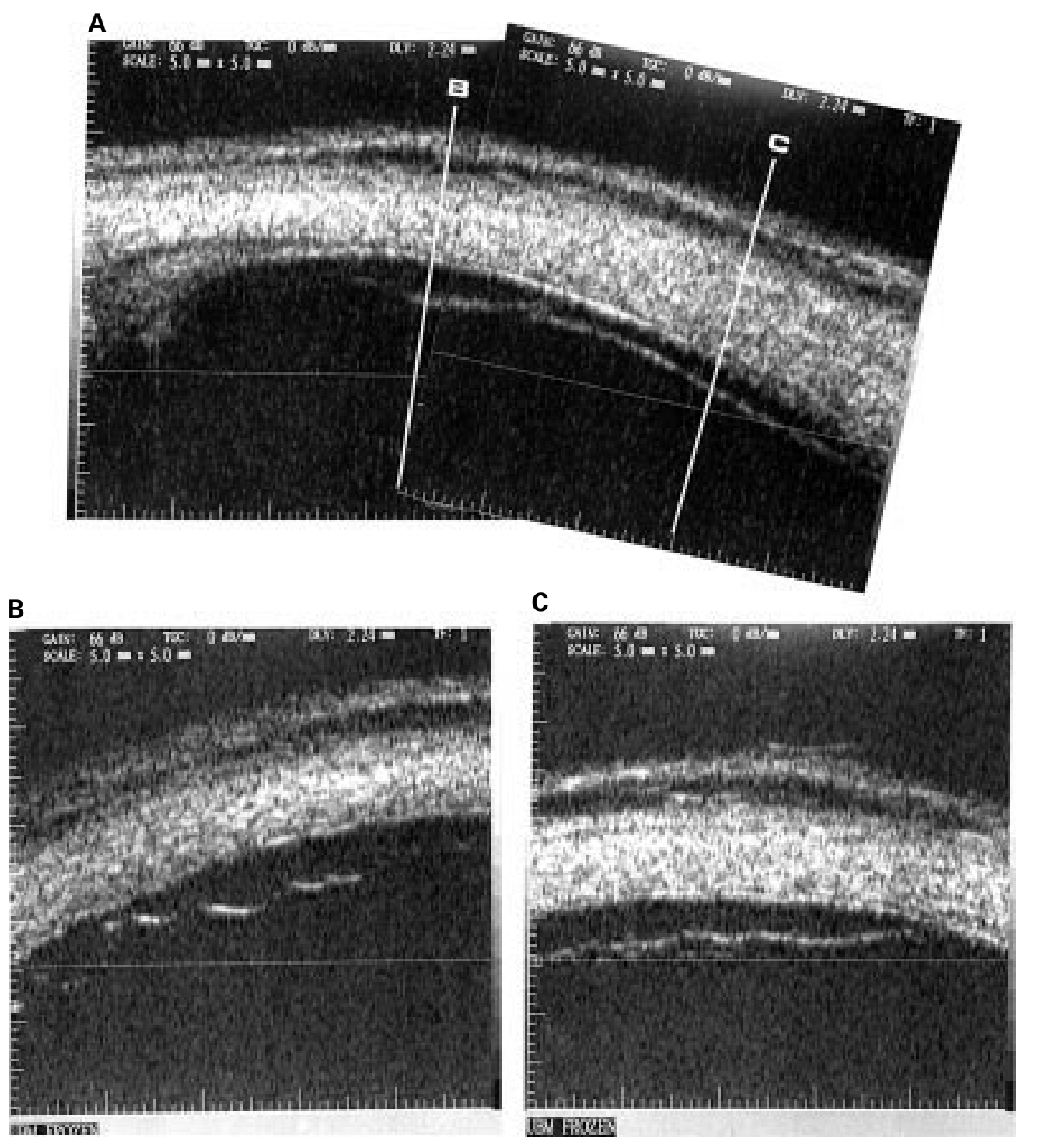

Figure 2 Patient no 10, left eye. (A) Composite cross sectional UBM image (5 o'clock). A cyst of the posterior third of the pars plana can be seen which extends to the ora serrata region continuing with schisis of the peripheral retina. (B) Transverse section of the posterior portion of the pars plana ciliaris. Numerous cysts can be seen forming a ragged profile with multiple convexities towards the vitreous. (C) Transverse section of the extreme retinal periphery. A hyperreflective slightly undulated linear area can be observed which represents schisis of the peripheral retina.

two lesions; retinoschisis was imaged as a single thin hyperreflective echo and retinal detachment as a thick and bilayered hyperreflective echo (Fig 4$).^{12}$

\section{Discussion}

UBM is a useful diagnostic tool not only in pathologies of the anterior segment but also of the posterior part of the ciliary body and of the peripheral retina. ${ }^{11} 1229$ The high resolution images allow a more detailed morphological study compared with "traditional" ophthalmoscopic study. Furthermore, examination is carried out in vivo, which is not possible by histopathological means.

In the 18 eyes, cross sectional study of the ciliary body and peripheral retina showed the close topographical and morphological relation between pars plana cysts and peripheral degenerative retinoschisis (Figs 1A, 2A, 3A). In the areas corresponding to retinoschisis pars plana cysts were numerous and so close to each other as to be adjoining. At times, there was a band of cystoid degeneration between the two lesions (Fig 1A).

In the literature, the prevalence of pars plana cysts in the general population has been reported as $16 \% .^{33}$ The association of pars plana cysts with retinoschisis comes from a few histological $^{2023}$ and clinical ${ }^{2}$ reports. Adams described primitive pars plana cysts like empty spaces between the ciliary pigment and nonpigment epithelium; anteriorly, these cysts were noted to extend variably over the pars plana towards the ciliary processes, and posteriorly they continued with an area of retinal cystoid degeneration beyond the ora. ${ }^{23}$ In our study using UBM similar alterations were observed in vivo.

Histochemical studies have shown that pars plana cysts are filled with hyaluronic acid as a result of an active secretory mechanism. ${ }^{19}$ The same substance is found in the cystoid spaces and schisis of the peripheral retina, ${ }^{18}$ but no 


\section{A}

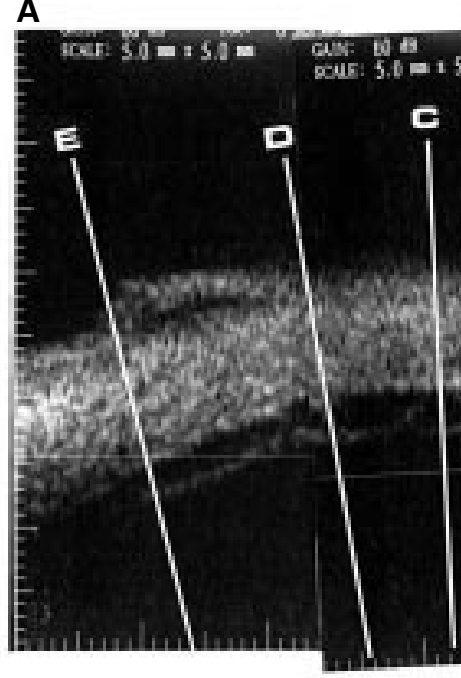

$205.24=$

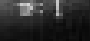



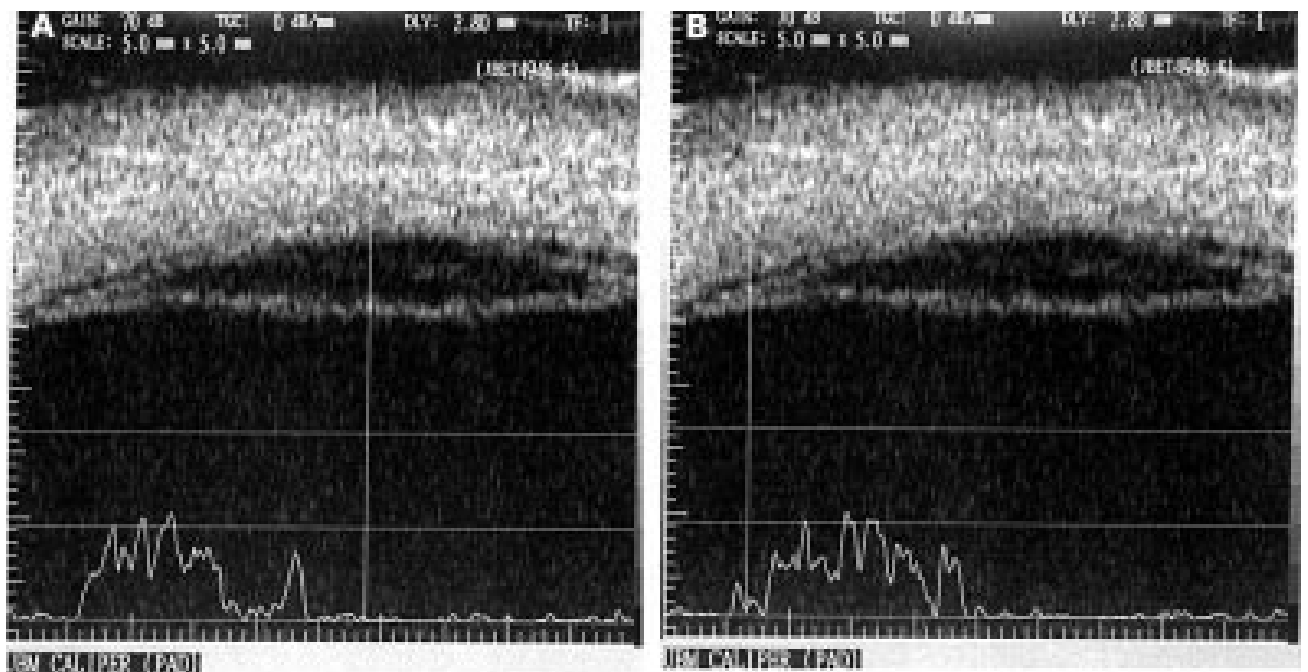

Figure 4 Patient no 12, left eye. Transverse section of the extreme retinal periphery showing retinoschisis and associated retinal detachment (at the left end of the picture). In (A) the vector of the A-scan is on the retinoschisis and in (B) it is on the retinal detachment.

PAS positive cells have been demonstrated within the walls of retinoschisis. ${ }^{17}$ These features and the close morphological relation imaged at UBM may suggest that fluid secreted at the level of the pars plana passes into the schisis cavity in the peripheral retina. Indeed, at the ora serrata the external limiting membrane, owing to the absence of the particles of the photoreceptors, gradually comes closer to the retinal pigment epithelium and just before the passage to ciliary tissue closely blends with the junctional structures joining the lateral cell walls of retinal pigment epithelium (Verhoeff membrane). ${ }^{34}$ Thus, the passage of cyst contents under the external limiting membrane would be hampered and the liquid would accumulate between the external limiting membrane and the inner retinal layers, causing retinoschisis.

On transverse sections pars plana cysts were distinguished in three main morphological types, based on the profile of their internal wall, as "isolated," "confluent," and "clustered." The "isolated" cysts were generally adjacent to each other, though maintaining their individuality. This is shown by the regular convex profile of the internal wall towards the vitreous; their dimensions were variable. The "confluent" cysts could suggest that two adjacent cysts become so close as to blend, thus giving the aspect of an irregular internal wall defining communicating cavities. However, the reason why some cysts join and others do not is not clear. The same process of lateral fusion could account for the "clustered" cyst type, where a single ragged line represents the internal wall of a single large cystic process extending for a few millimetres. This picture resembles that described ophthalmoscopically by Schepens as "schisis of the pars plana." 22

UBM has contributed to the detailed study of pars plana cysts and peripheral retinoschisis in vivo giving further insight to the morphology of these lesions and their association.
1 Shea M, Schepens CL, Von Pirquet SR. Retinoschisis. I. Senile type: a clinical report of one hundred seven cases. AMA Arch Ophthalmol 1960;63:25-33.

2 Byer NE. Clinical study of senile retinoschisis. Arch Ophthalmol 1968;79:36-44.

3 Straatsma BR, Foos RY. Typical and reticular degenerative retinoschisis. 1973;75:551-75.

4 Byer NE. Peripheral retinal lesions related to rhegmatogenous retinal detachment. In: Guyer DR, Yannuzzi LA, Chang S, Shields JA, Green WR, ed. Retina, vitreous, macula. 1st ed. Philadelphia: Saunders, 1999:1073-98.

5 Lean JS. Diagnosis and treatment of peripheral retinal Lean JS. Diagnosis and treatment of peripheral retinal
lesions. In: Freeman WR, ed. Practical atlas of retinal disease lesions. In: Freeman WR, ed. Practical atlas of retinal
and therapy. New York: Raven Press, 1993:211-2.

6 Scuderi G, Morone G, Brancato R. Atlante di oftalmoscopia Scuderi G, Morone G, Brancato R. Atlante di
clinica. Milan: Masson Italia, 1986:177-92.

7 Colyear B. Differential diagnosis of "dome-shaped" retinoschisis. Bibl Ophthalmol 1967;72:189-91.

8 Kylstra JA, Holdren DN. Indirect ophthalmoscope perimetry in patients with retinal detachment or retinoschisis. Am f Ophthalmol 1995;119:521-2.

9 Culver Boldt H, Brown DM, McGeorge AJ. Echographic diagnosis of degenerative retinoschisis facilitated by scleral indentation. Am F Ophthalmol 1994;118:123-4.

10 Hillman JS, Ridgway AEA. Retinoschisis and retinal detachment: an ultrasonic comparison. Bibl Ophthalmol 1975;83:63-7.

11 Pavlin C J, Foster FS. Ultrasound biomicroscopy of the eye. New York: Springer-Verlag, 1995.

12 Gentile RC, Berinstein DM, Liebmann J, et al. HighGentile RC, Berinstein DM, Liebmann J, et al. High-
resolution ultrasound biomicroscopy of the pars plana and resolution ultrasound biomicroscopy of the pars pl
peripheral retina. Ophthalmology 1998;105:478-84.

13 Foos RY. Senile retinoschisis: relationship to cystoid degeneration. Trans Am Acad Ophthalmol Otolaryngol 1970;74: 3-50; discussion 50-1.

14 Balacco-Gabrieli C, Paglierini S. Peripheral retinal degeneration. In: Hamilton AMP, Gregson R, Fish GE, eds. Text atlas of the retina. London: Martin Dunitz, 1998: 379-84

15 Feman SS, Stevens Andrews J, James M, et al. Human biochemical components in retinoschisis and detachment. Arch Ophthalmol 1981;99:475-7.

16 Cibis PA. Retinoschisis - retinal cysts. Trans Am Ophthal Soc 1965;63:417-53.

17 Harris GH. Retinoschisis: pathogenesis and treatment. Canad f Ophthalmol 1968;3:312-8.

18 Zimmerman LE, Spencer WH. The pathologic anatomy of retinoschisis. AMA Arch Ophthalmol 1960;63:34-43.

19 Zimmerman LE, Fine BS. Production of hyaluronic acid by cysts and tumors of the ciliary body. Arch Ophthalmol 1964;72:365-79.

20 Yanoff $M$ and Fine BS. Ocular pathology. 2nd ed. Philadelphia: Harper and Row Publishers, 1982:408-9, 504-13.

21 Richards JSF, Harris GS. Retinoschisis treated by photocoagulation. Canad F Ophthalmol 1967;2:199-202.

22 Allen RA, Miller DH, Straatsma BR. Cysts of the posterior ciliary body (pars plana). Arch Ophthalmol 1961;66:36-47.

23 Adams ST. Pars plana cysts. AMA Arch Ophthalmol 1957;58:328.

24 Schepens CL. Examination of the ora serrata region: its clinical significance. Acta Conc Ophthal XVI Britannia 1950;2:1384.

25 Davidson S. Spontaneous cysts of the ciliary body. $\mathrm{Br} F$ Ophthalmol 1960;44:461.

26 Pavlin CJ, Sherar BA, Foster FS. Subsurface ultrasound microscopic imaging of the intact eye. Ophthalmology 1990;97:244-50. 
27 Pavlin CJ, Harasiewicz K, Sherar MD, et al. Clinical use of ultrasound biomicroscopy. Ophthalmology 1991;98:287-95. 28 Marigo FA, Esaki K, Finger PT, et al. Differential diagnosis of anterior segment cysts by ultrasound biomicroscopy.

29 Liu W, Wu Q, Huang S, et al. Ultrasound biomicroscopic features of anterior proliferative vitreoretinopathy. Retina 1999;19:204-12

30 Tanaka S, Takeuchi S, Ideta H. Ultrasound biomicroscopy for the detection of breaks and detachment of the ciliary epithelium. Am f Ophthalmol 1999;128:466-71.
31 Yoshida S, Sasoh M, Arima M, et al. Ultrasound biomicroscopic view of detachment of the ciliary epithelium in retinal detachment with atopic dermatitis. Ophthalmology 1997; 104:283-7.

32 Ossoinig KC. Standardized echography: basic principles, clinical applications, and results. Int Ophthalmol Clin 1979; 19:127-210

33 Okun E. Pathology in autopsy eyes. Am f Ophthalmol 1960; 50:424.

34 Hogan MJ, Alvarado JA, Weddel JE. Histology of the human eye. Philadelphia: Saunders, 1971:410-15, 498-507.

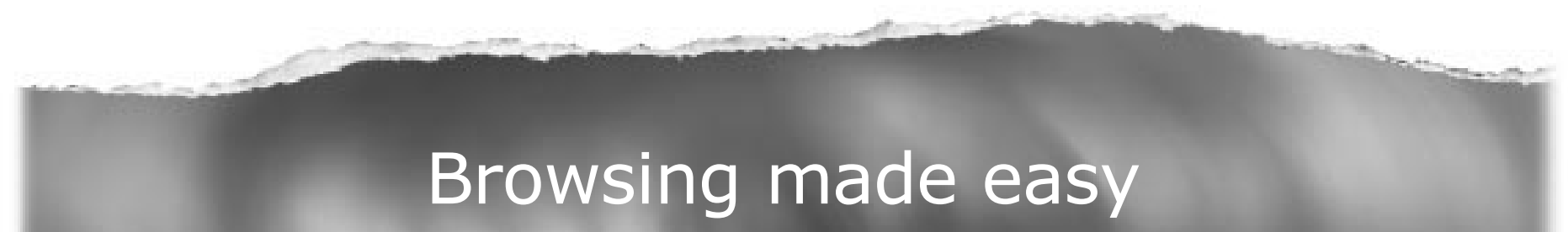

\section{Collections}

With a single click Collections allows you to find all articles that have been published in your chosen subject. Select from over 200 clinical and non-clinical topic collections and/or cross search other specialist journals, the BMJ and Cochrane Reviews

\section{www.bjophthalmol.com}

